\title{
COLETA SELETIVA E EDUCAÇÃO AMBIENTAL: RECICLAR VALORES E REDUZIR O LIXO
}

\author{
FRIEDE, Roy Reis (Brasil, Rio de Janeiro, Rio de Janeiro) ${ }^{1 *}$; \\ REIS, Danielle de Souza (Brasil, Rio de Janeiro, Rio de Janeiro) ${ }^{2 *}$; \\ AVELAR, Katia Eliane Santos (Brasil, Rio de Janeiro, Rio de Janeiro) ${ }^{2 * *}$; \\ MIRANDA, Maria Geralda de (Brasil, Rio de Janeiro, Rio de Janeiro) ${ }^{2}$ \\ ${ }^{1}$ Universidade Federal do Estado do Rio de Janeiro \\ ${ }^{2}$ Centro Universitário Augusto Motta \\ ORCID ID: http://orcid.org/0000-0001-9316-3690* \\ ORCID ID: https://orcid.org/0000-0002-0007-0397* \\ ORCID ID: http://orcid.org/0000-0002-7883-9442** \\ ORCID ID: https://orcid.org/0000-0002-2461-7414*
}

\begin{abstract}
RESUMO
Este artigo é resultado de pesquisa aplicada com vistas à Educação Ambiental com alunos de uma escola pública no Rio de Janeiro. Efetivamente, percebe-se que a cultura da população da cidade ainda está pautada no descarte inapropriado dos resíduos sólidos, bastando para isso observar os espaços públicos. A escolha de uma escola para realizar o projeto foi por entender que este é o lugar da produção do conhecimento e da conscientização. Utilizou-se a Metodologia da Problematização, embasada no Método do Arco, de Charles Maguerez, que procura problematizar a realidade, ou um recorte dela, com vistas à sua transformação. Para isso, foi proposto aos alunos que separassem determinados materiais descartados em sua residência, trazendo-os para a escola por um período determinado. Foram instaladas caixas coletoras no pátio da escola para o depósito dos resíduos solicitados. A partir dessa ação, iniciou-se um processo de Educação Ambiental, por meio de oficinas e com material didático confeccionado para esse fim. A metodologia adotada no trabalho buscou contemplar diferentes disciplinas, de modo a conscientizar e formar novos hábitos nos alunos sobre resíduos sólidos residenciais no pós-consumo, mas também em um momento anterior, que é o de consumo consciente.
\end{abstract}

\section{PALAVRAS-CHAVE}

Educação. Educação Ambiental. Sustentabilidade.

\section{SELECTIVE COLLECT AND ENVIRONMENTAL EDUCATION: RECYCLE VALUES AND REDUCE WASTE}

\begin{abstract}
This article is a result of applied research with a view to Environmental Education with students from a public school in Rio de Janeiro. Effectively, it is noticed that the culture of the population of the city is still based on the inappropriate disposal of solid waste, just by observing the public spaces. The choice of a school to carry out the project was to understand that this is the place to produce knowledge and awareness. It was used the Methodology of Problematization, based on the Method of the Arc, by Charles Maguerez, who seeks to problematize reality, or a cut of it, with a view to its transformation. For this,
\end{abstract}


students were proposed to separate certain discarded materials at their residence, bringing them to school for a specified period. Collecting boxes were installed in the school yard for students to deposit the requested waste. From this action an Environmental Education process was initiated, through workshops, with didactic material made for this purpose. The methodology adopted in the work sought to contemplate different disciplines, in order to raise awareness and form new habits in students about residential solid waste in post-consumption, but also in an earlier moment, that of the conscious consumption.

\title{
KEYWORDS
}

Education. Environmental Education. Sustainability.

\section{COLECTA SELECTIVA Y EDUCACIÓN AMBIENTAL: RECICLAR VALORES Y REDUCIR LA BASURA}

\begin{abstract}
RESUMEN
Este artículo es el resultado de la investigación aplicada con vistas a la Educación Ambiental con alumnos de una escuela pública en Río de Janeiro. En realidad, se percibe que la cultura de la población de la ciudad todavía está pautada en el descarte inapropiado de los residuos sólidos, bastando para ello observar los espacios públicos. La elección de una escuela para realizar el proyecto fue por entender que este es el lugar de la producción del conocimiento y de la concientización. Se utilizó la Metodología de la Problematización, basada en el Método del Arco, de Charles Maguerez, que busca problematizar la realidad, o un recorte de ella, con miras a su transformación. Para ello, se propuso a los alumnos que separaran determinados materiales desechados en su residencia, trayéndolos a la escuela por un período determinado. Se instalaron cajas colectoras en el patio de la escuela para el depósito de los residuos solicitados. A partir de esa acción se inició un proceso de Educación Ambiental, por medio de talleres y con material didáctico confeccionado para ese fin. La metodología adoptada en el trabajo buscó contemplar diferentes disciplinas, de modo a concientizar y formar nuevos hábitos en los alumnos sobre residuos sólidos residenciales en el posconsumo, pero también en un momento anterior, que es el de consumo consciente.
\end{abstract}

PALABRAS CLAVE

Educación. Educación Ambiental. Sostenibilidad.

\section{INTRODUÇÃO}

Existe um consenso de que medidas urgentes devem ser adotadas para minimizar os efeitos maléficos do descarte inadequado, já que tanto a quantidade quanto a qualidade dos resíduos sólidos produzidos (mais ou menos tóxicos) são importantes, mas a forma de geri-los é primordial. Nesse aspecto, há a necessidade de entender

Educação \& Formação, Fortaleza, v. 4, n. 11, p. 117-141 maio/ago. 2019

DOI: https://doi.org/10.25053/redufor.v4i11.924

http://seer.uece.br/redufor 
como a questão dos resíduos sólidos transformou-se em um problema de grande dimensão nas metrópoles, bem como os fatores que influenciam sua geração.

A relação atual das pessoas com os resíduos sólidos é resultado de um processo histórico, envolvendo fatores econômicos, sociais, culturais e tecnológicos. Os resíduos gerados antes do sedentarismo humano eram reintegrados aos ciclos naturais como adubo, sendo o material decomposto pelos micro-organismos e transformado em nutrientes para outras formas de vida. No entanto, a partir do momento em que grupos humanos deixam de ser nômades e passam a ser sedentários, fixando-se em aldeias (onde as necessidades de energia e alimento aumentam), começam a acumular resíduos (ROCHA; ROSA; CARDOSO, 2009).

Os resíduos sólidos, à exceção de excretas corporais e restos de alimentos, tiveram sua origem com uma inovação da espécie humana, junto ao sedentarismo alcançado pela prática da agricultura e desenvolvimento da comunicação simbólica (linguagem). A criação de ferramentas, que se tornaram cada vez mais complexas, foi potencializando transformações cada vez maiores no ambiente natural (PUCCI, 2013).

A preocupação ambiental com os danos causados pelos resíduos sólidos vem modificando a forma de defini-los, a forma de gerenciá-los e as técnicas de tratamento. Na concepção sustentável, como observável na Lei de Resíduos Sólidos (BRASIL, 2010), o resíduo sólido é uma etapa dentro do "ciclo de vida do produto", definido no artigo $3^{\circ}$, do capítulo II, inciso IV, da Lei n. 12.305/2010, como "[...] uma série de etapas que envolvem o desenvolvimento do produto, a obtenção de matérias-primas e insumos, o processo produtivo, o consumo e a disposição final”; esta última etapa só deve ocorrer depois de satisfeitas todas as possibilidades de reuso e reciclagem.

Tal ideia ainda é oposta à definição popular culturalmente absorvida pelas pessoas, que aproxima a definição de "lixo" ao conceito de descarte proeminente em um tempo cada vez menor. Nesse aspecto, verifica-se que a Lei n. 12.305/2010 é muito importante, mas ela por si só não garante a conscientização das pessoas, que têm papel importante tanto em relação ao consumo quanto no descarte consciente. É necessário, primeiramente, uma reformulação no próprio conceito de resíduo sólido como algo distinto de rejeito, pois o resíduo sólido é uma etapa do processo produtivo, é um estado da matéria potencialmente útil, o qual pode novamente dispor de serventia, bastando uma ação para tal (reuso), ou mesmo podendo reintegrar-se ao ciclo produtivo 
(reciclagem), retornando a ser matéria-prima e poupando a extração de novos recursos naturais. Já o rejeito é o resíduo que não pode ser reaproveitado, que é descartado por não ter outra utilidade em nenhuma hipótese.

Partindo dessas constatações, a pesquisa apresentada neste artigo teve como um de seus objetivos despertar 0 interesse dos alunos para o tema da educação ambiental e, mais especificamente, da importância do adequado descarte de resíduos sólidos. Para desenvolver o processo de educação ambiental, foram realizadas oficinas abordando a importância de realizar a coleta seletiva, o material passível de ser reciclado, as cores simbólicas para o descarte de cada tipo de matéria, o valor financeiro dos recicláveis e a importância de implementar o que está disposto na Lei n. 12.305/2010.

Foi possível perceber, ao final da atividade proposta, que os alunos objeto desta pesquisa, adolescentes em processo de formação, realizaram a coleta seletiva como cidadãos, conscientes de seus direitos e deveres.

\section{INOVAÇÃO E CONSUMO: PARADIGMAS CONTEMPORÂNEOS}

Com a Revolução Industrial, iniciada no século XVIII na Inglaterra e ampliada para o mundo, houve um aumento do volume de resíduos sólidos, bem como uma elevação populacional (em razão dos avanços da medicina) e aumento da população urbana, que se deslocava para a cidade. Apesar das primeiras cidades terem surgido há aproximadamente 3.500 anos antes de Cristo (a.C.), após a chamada Revolução Agrícola, é a partir da Revolução Industrial, no século XVIII, na Europa, que ocorre o processo de urbanização moderno. Nos países dos demais continentes, esse fenômeno foi intensificado após a Segunda Guerra Mundial e está diretamente ligado à industrialização e ao capitalismo (BODAH, 2012).

A produção em massa permitiu o acesso de grande parte da população aos produtos que chegavam ao mercado, ao mesmo tempo que "criava" novas necessidades para os indivíduos, que passaram a incorporar a valorização do descartável. A sociedade moderna é caracterizada como sociedade de consumo, pois, embora a cultura material e o consumo estejam presentes em qualquer sociedade, após a Revolução Industrial as pessoas começaram a elevar ao status de "necessidades" elementos supérfluos à sua sobrevivência. 
Mas vale destacar que a obsolescência não apresentava a velocidade conhecida no século $\mathrm{XX}$, com o desenvolvimento da capacidade de uso não energético do petróleo e o surgimento dos polímeros sintéticos, que inauguraram uma nova classe de resíduos sólidos e, mais do que isso, inauguraram uma mudança cultural profunda, que aceita descartar e não reparar os objetos, aumentando mais a geração de resíduos sólidos per capita (PUCCl, 2013).

Após a Revolução Industrial, houve uma radical transformação no modo de gerir a produção de bens de consumo. A organização fabril nos moldes fordista, consoante Kumar (2006), não teve paralelo em sua capacidade de produzir bens padronizados e em escala de massa. Tudo isso estava muito bem enquanto havia grupos suficientes na população ainda à espera por sua vez de consumir os frutos da produção industrial, mas, com o passar do tempo, esses novos grupos de consumidores, ávidos por produtos padronizados, esgotam-se. Nesse momento, as demandas por produtos mudam de forma, passam a ser guiadas pelos ditames da moda, de novos estilos de vida, de inovação tecnológica ininterrupta, e exigem rápido giro de pessoal e alterações imediatas na produção. Obviamente que essa nova situação se ajusta aos requisitos das empresas capitalistas modernas, sempre à procura de novas maneiras de explorar e expandir mercados (KUMAR, 2006).

Para alcançar novos consumidores, considerando-se que a produção em massa já havia satisfeito em grande parte as necessidades do mercado consumidor, surge a flexibilidade como palavra-chave, vindo com ela a noção de inovação, a fim de possibilitar que o mercado continuasse crescendo. A Organização para Cooperação e Desenvolvimento Econômico (OCDE, 1996) define inovação tecnológica de forma bem abrangente, enfatizando que esse conceito resulta no desenvolvimento de produtos ou processos tecnologicamente novos ou substancialmente melhorados:

\begin{abstract}
Inovação tecnológica de produto ou processo compreende a introdução de produtos novos e melhorias significativas em produtos e processos existentes. [...] Atividades inovativas compreendem todos os passos científicos, tecnológicos, organizacionais, financeiros e comerciais, inclusive o investimento em novos conhecimentos, que, efetiva ou potencialmente, levem à introdução de produtos ou processos tecnologicamente novos ou substancialmente melhorados. (OCDE,1996, p. 35; 44).
\end{abstract}

Tigre (2006) apresenta três fatores preponderantes para a mudança do paradigma de crescimento dentro dos parâmetros do fordismo: primeiro, o aumento 
sucessivo nos preços do petróleo a partir da crise de 1973, mostrando que um modelo pautado no consumo crescente de materiais e energia não era sustentável. Desde a Segunda Guerra Mundial, uma trajetória de inovações e busca de economia de energia passou a ser buscada.

Segundo, porque o modelo fordista de produção estava baseado na padronização e divisão do trabalho, enquanto o Japão já liderava a trajetória de inovações para redução de desperdício, aumento de qualidade, cooperação intra e interindustrial e uso intensivo de informação e conhecimento.

Por fim, o terceiro e mais importante: a invenção do transistor na década de 1940, potencializado pela introdução do circuito integrado nos anos 70 e pela internet nos anos 90. Com a microeletrônica servindo de base técnica, surgiram as tecnologias de informática, telecomunicações, optoeletrônica, software e broadcasting, bem como outras que alimentam o processo de inovação. Assim, o fordismo, que desde o início do século fora bem-sucedido, vai sendo substituído pela "onda de destruição criadora" (TIGRE, 2006), que traz a informação e o conhecimento em seu centro. Esses dois itens são considerados por muitos estudiosos como o centro da Terceira Revolução Industrial, enquanto as duas primeiras Revoluções giraram em torno da energia (vapor e eletricidade):

\footnotetext{
Diferente do fordismo, que é intensivo no uso de energia e materiais, a nova onda de destruição criadora é intensiva em informação e conhecimento. Essa 'revolução em miniatura' caracteriza uma trajetória de inovações associada à aplicação da microeletrônica e à busca de novos materiais. (TIGRE, 2006, p. 54).
}

Os produtos eletrônicos, como computadores, celulares, notebooks, câmeras digitais, MP3 players, entre outros, funcionam como canais da informação e conhecimento. Esses utilitários, portanto, acabam tendo uma demanda crescente. É importante ressaltar o papel central das tecnologias de base microeletrônica como carros-chefe da economia mundial. Hoje as corporações globais mais lucrativas e que apresentam maiores taxas de crescimento não são mais os gigantes dos paradigmas fordistas, mas sim "um tipo de empresa que não existia há três décadas”. A expressão “[...] 'wintelismo' (junção de Windows + Intel) vem sendo usada para substituir tanto o 'fordismo' quanto o 'taylorismo' na caracterização do novo paradigma técnico-econômico, dando ênfase ao caráter internacional das novas trajetórias de inovação" (TIGRE, 2006, p. 57).

Educação \& Formação, Fortaleza, v. 4, n. 11, p. 117-141 maio/ago. 2019 
Não há dúvidas de que a inovação tecnológica tornou-se o grande motor da economia. Os eletrônicos são os produtos desse novo modelo, representando novidades ininterruptas, seja de design ou de recursos tecnológicos. O indivíduo, por sua vez, orientado pelo trabalho do marketing, não quer estar desatualizado da era digital, adquirindo, cada vez em tempo menor, novos produtos digitais. Assim, uma questão se impõe: o que será feito dos resíduos sólidos, em especial do "lixo eletrônico", que cresce em volume exponencial e é altamente tóxico?

Permeado por aspectos econômicos, psicológicos, estéticos e culturais, o consumo adquire uma conotação para além da garantia de subsistência:

\begin{abstract}
O consumo é sempre e em todo lugar um processo cultural, mas 'cultura do consumo' é singular e específica: é o modo dominante de reprodução cultural desenvolvido no Ocidente durante a modernidade. [...] está ligada a valores, práticas e instituições fundamentais que definem a modernidade ocidental, como a opção, o individualismo e as relações de mercado. (SLATER, 2002, p. 17).
\end{abstract}

O Ministério do Meio Ambiente reconhece o poder que o consumismo exerce no nível psíquico e social dos seres humanos: os indivíduos passam a ser "[...] reconhecidos, avaliados e julgados por aquilo que consomem, aquilo que vestem ou calçam, pelo carro e pelo telefone celular que exibem em público. O próprio indivíduo passa a se autoavaliar pelo que tem e pelo que consome" (BRASIL, 2005, p. 15).

É possível perceber que os valores socialmente normatizados são internalizados pelos indivíduos, criando identidades sociais e uma semântica subjetiva da representação do ser pelos objetos adquiridos (status no grupo). Essas noções estão arraigadas na cultura da sociedade, bem como nas atitudes dos indivíduos. Nesse cenário, ganha destaque a publicidade, como propulsora do consumismo, estimulando desejos e tornando as necessidades construídas em aportes simbólicos, os quais são carregados de componentes estéticos e psíquicos, em que se configura a cultura do consumo.

\footnotetext{
A lógica capitalista apresenta-se fundamentada em dois pilares: a produção e o consumo; e a sociedade contemporânea está imersa nessa dicotomia, que contrapõe $o$ ato de produzir, selvagem e impessoal, e o consumir, cada vez mais customizado, sedutor, belo e idealizado. Entre a produção e o consumo, como um elo de ligação entre o produto e o desejo, situa-se a publicidade. Pela publicidade, um produto múltiplo e impessoal se transforma em algo único, nomeado, particular, próprio para cada comunidade. A publicidade é o lugar onde o produto ganha vida, nome, existência, identidade e substância. A transformação de um mero produto em objeto de desejo é operacionalizada de forma cada vez mais contundente, de tal modo que o fenômeno do consumo e sua dimensão subjetiva são bem maiores que a dimensão produtiva. (MARANHO; RIBEIRO, 2008, p. 4).
}

Educação \& Formação, Fortaleza, v. 4, n. 11, p. 117-141 maio/ago. 2019 
Com a globalização, a cultura do consumo, que era restrita ao Ocidente, deixa de concentrar-se nos seus domínios, alcançando todo o mundo. Como uma forma de dominação e pressuposto de civilização, esse modelo impõe-se como um projeto universal da modernidade ocidental, com alcances globais. Não obstante, a promessa da globalização, que embutia a distribuição do conhecimento e da tecnologia, radicalizou-se pela concorrência desleal, porque entre desiguais. "Desde a Ásia xiita e muçulmana, no oriente hinduísta ou budista, entre a cristandade europeia e a americana, e mesmo na miserável África politeísta, os deuses da atualidade são o dinheiro, o consumo [...] envolvidos pelo fetiche dos produtos e das marcas" (YUNES, 2001, p. 9).

Muitos pesquisadores têm discutido os prejuízos que esse modelo causa ao ambiente, uma vez que a vida na Terra não teria condições de suportar um modelo altamente destrutivo como o atual, adotado em escala global, notadamente agravado pelo descarte inapropriado e pela falta de políticas públicas que incentivem uma mudança de postura por parte dos cidadãos e das empresas.

Miller (2005) compara o planeta Terra a uma astronave, deslocando-se a cem mil quilômetros por hora pelo espaço sideral, sem possibilidade de parada para abastecimento, o que causaria problemas sérios, em médio e longo prazo, para a manutenção da vida de sua população. Os passageiros, utilizando-se da inesgotável energia solar, processariam, por meio de sua tecnologia e de seu metabolismo, os recursos naturais finitos, gerando, inexoravelmente, algum tipo de poluição (MILLER, 2005). O autor ressalta ainda que da existência de um eficiente sistema de aproveitamento de energia solar e de reciclagem da matéria e do equilíbrio entre população, recursos naturais e poluição dependerá o nível de qualidade de vida no planeta (MILLER, 2005).

Verifica-se, pois, a imposição de um novo paradigma, o paradigma da sustentabilidade, seja pela limitação dos recursos não renováveis, seja pela incapacidade de regeneração do planeta, ou pela própria superação da ideia psíquica de que consumo é igual à felicidade.

Como diz Cobra (2004), a angústia da luta pela posse de bens passa a ser substituída pela angústia da falta de tempo, ou mesmo da falta da dimensão exata do seu eu. O ser humano é, portanto, um eterno insatisfeito. Quando ele consegue chegar ao cume do consumo e passa a dispor de todos os bens que ansiava, "[...] ele percebe que a felicidade não vem de fora, mas está e sempre esteve dentro dele" (COBRA, 2004, p. 100). 
A pergunta é: como caminhar rumo ao novo paradigma da sustentabilidade? Necessita-se de uma reformulação do próprio conceito de resíduo sólido como algo distinto de rejeito, pois o resíduo sólido é uma etapa do processo produtivo, é um estado da matéria, potencialmente útil, o qual pode novamente dispor de serventia, bastando uma ação para tal (reuso), ou mesmo podendo reintegrar-se ao ciclo produtivo (reciclagem), retornando a ser matéria-prima e poupando a extração de novos recursos naturais. Olhar o resíduo sólido como algo desprovido de valor é uma forma ultrapassada de lidar com a matéria-prima e que leva a consequências nocivas ao meio ambiente do qual o Homem faz parte.

\section{PENSAMENTO COMPLEXO: O HOMEM COMO PARTE DO MEIO AMBIENTE}

A partir da década de 1960, intensifica-se a preocupação com a sobrevivência da espécie humana, dado o avanço da destruição da natureza, deixando o tema de ser restrito, pois grande parte da humanidade, ainda que de forma antropocêntrica, teme por seu destino, e mesmo aqueles que defendem o capitalismo como modelo econômico reconhecem que sua dinâmica de extração crescente dos recursos naturais depende de uma revisão de seus pilares para permanecer por mais tempo.

Historicamente, até a década de 1970, a ecologia ocupou-se do equilíbrio entre os ecossistemas, das relações entre os seres vivos e não vivos, sem considerar as questões socioeconômicas e suas influências no meio ambiente. A ação do Homem era reconhecida em seus efeitos, deixando de analisar suas causas, bem como as possíveis estratégias corretivas. Essa visão reducionista, empregada na educação conservacionista, tem o manejo dos recursos naturais como tema. Seu conteúdo provém das ciências biológicas e da crença de que a tecnologia detém grande potencial para sanar os desequilíbrios ambientais.

Com o passar do tempo, a Ecologia foi dialogando com outras ciências e percebeu-se que esta, sozinha, não possuía os necessários conhecimentos para a resolução de problemas tão complexos, intrínsecos à política, à cultura e ao modelo socioeconômico. A Educação Ambiental, posterior ao ensino da Ecologia, indica a urgência em promover uma educação para a formação ou mudança de valores individuais e sociais, com ações concretas e pautadas no reconhecimento da 
responsabilidade de cada cidadão, por meio do conhecimento e da identificação com as questões ambientais.

Em virtude de a crise ambiental adquirir uma escala global, assume-se a questão como pauta de planejamento político e econômico, nacional e transnacional, com frequentes conferências internacionais.

Existem inúmeros enfoques dados à questão ambiental, no entanto é importante diferenciá-los, para entender o conceito da Educação Ambiental, seus objetivos, prerrogativas e propostas. De acordo com Mello e Souza (2000, p. 3-4):

[...] além das resistências sociais normais, do descaso de muitos e da indiferença de tantas empresas e tantas instituições, constata-se o fato preocupante de haver, mesmo entre os interessados, confusão de discurso, imprecisão de conceitos, omissão de áreas de estudo. [...] A Educação Ambiental sofre com essas ambivalências, essas omissões teóricas e o singular fracionamento de significações, seu propósito é danificado. O objetivo de contribuir para a melhoria da consciência crítica, em relação à crise ecológica, registra o dano. Pulveriza e debilita a ação corretiva.

Após a Eco-92, inúmeros cursos e ações na área da educação ampliaram-se pelo Brasil e pelo mundo, denominadas equivocadamente de Educação Ambiental, abarcando quase que indiscriminadamente qualquer ação relacionada ao meio ambiente (FERRAZ, 2004).

Ferraz (2004) distingue três enfoques da Educação Ambiental, alertando para o fato de que poucos estejam realmente comprometidos com uma mudança de valores de vida: a educação "sobre o meio ambiente", por exemplo, é uma mera descrição de fenômenos ambientais, não podendo ser denominada como Educação Ambiental, embora assim sendo considerada na primeira parte da evolução histórica da Educação Ambiental, quando ainda muito naturalista e biológica. Pode-se dizer que a mesma era politicamente neutra, apolítica e fragmentada (FERRAZ, 2004).

A educação "no meio ambiente" consiste na passagem da informação no meio ambiente, de forma descritiva e separada de um contexto maior, a exemplo da visita a uma reserva biológica (FERRAZ, 2004).

A Educação "para o meio ambiente", que é a educação mais abrangente, incluindo o meio ambiente em sua totalidade (natural, social, política, econômica e cultural), com uma abordagem holística das questões ambientais (FERRAZ, 2004). 
Um professor de Biologia, Geografia, História e Ecologia não necessariamente será um educador ambiental. A simples transmissão de informação, sem abertura à participação, por meio da sensibilização e engajamento na resolução, não surtirá efeitos significativos. É importante possibilitar que se desenvolva no indivíduo o entendimento de que todos são afetados reciprocamente pelas ações individuais e coletivas: os hábitos, a emissão de poluentes, a escassez ou abundância de chuvas, o esgotamento dos recursos naturais. A definição formulada por Ferraz (2004, p. 152) é esclarecedora:

\begin{abstract}
A educação ambiental é, portanto, levar as pessoas a repensar os valores que nos foram impostos por uma cultura de exploração da natureza e do homem, como se não fizéssemos parte desta natureza, e cujos resultados têm levado à degradação ambiental e milhões de seres humanos à miséria e fome.
\end{abstract}

A Educação Ambiental não deve ser apolítica, permitindo aos futuros cidadãos o exercício de direitos e deveres, necessário para garantir um ambiente limpo e saudável.

A educação tem um grande desafio, em pensar como ajudar na formação desse novo Homem, ser integrado ao meio ambiente, consciente de sua responsabilidade na preservação do meio ambiente e das consequências de suas ações, com as reflexões sobre as prerrogativas do sentido da vida. Na construção desse novo pensamento, que é contrário e complementar ao vigente, procura-se uma dissolução das fronteiras entre conhecimentos, capaz de interligá-los e contextualizá-los, juntando o que foi fragmentado, reintegrando o Homem à natureza.

Em meados do século $X X$, observou-se uma preocupação efetiva para com as questões ambientais, notadamente para a Educação Ambiental. Soares (2000) considera que os currículos, frente à acelerada e urgente tragédia ambiental, não tiveram o tempo necessário à maturação e decantação. As ações desenvolvidas tinham por objetivo corrigir danos concretos e urgentes.

Como a Educação Ambiental é a educação aplicada às questões ambientais, faz-se necessário o conhecimento das diversas correntes pedagógicas, com sua filosofia, teoria e história da educação, seus objetivos e princípios, para possibilitar uma visão mais completa acerca da área, sua fundamentação teórica, suas prerrogativas e possibilidades, evitando-se confusões metodológicas. De acordo com a posição que adotam em relação aos condicionantes sociopolíticos da escola, as tendências pedagógicas podem ser classificadas como liberais e progressistas (LIBÂNEO, 1998). 
$\mathrm{Na}$ Pedagogia Liberal, as questões relativas ao meio e aos temas interdisciplinares não estão de acordo com essa concepção, visto que nela o conteúdo enciclopédico pontual é valorizado, não havendo espaço para as relações de reciprocidade, de respeito ao outro em suas potencialidades e limitações (BRAVO, 2004).

$\mathrm{Na}$ Tendência Neoliberal, seus seguidores fazem uma ponte entre a educação de qualidade para o exercício da ocupação profissional. Nessa perspectiva, os ideais de cooperação e solidariedade cedem lugar à competitividade e meritocracia, fundamentais aos níveis elevados de produtividade (LUDWING, 2000 apud BRAVO, 2004). Mantém-se o aluno no nível do senso comum, separando-se o pedagógico das vinculações políticas, do entorno, da pesquisa.

Em oposição à Pedagogia Liberal, apresenta-se a Pedagogia Progressista, composta por tendências nas quais a educação está inserida no contexto das relações sociais. Essa corrente busca estabelecer um diálogo entre a escola e as necessidades sociais, questionando a relação dos homens entre si e entre estes com a natureza, buscando transformá-las (BRAVO, 2004). Defende-se, nessa concepção, o desenvolvimento de temas geradores, obtidos a partir de discussões sobre a realidade vivida pelos alunos, desenvolvendo neles um pensamento crítico.

Esse processo de ensino-aprendizagem vem mostrando-se hábil a trazer e conduzir as questões ambientais para a sala de aula. Como representante dessa corrente, aponta-se Piaget, que discorre sobre o desenvolvimento do raciocínio e dos valores morais, sobretudo reciprocidade e relação de respeito ao outro.

A escola progressista, entretanto, não se esgota no presente, vislumbrando nos alunos a ampliação das aspirações atuais, pautadas em ações rumo a um futuro mais promissor, conforme a Pedagogia de Freire (1980, p. 34):

\footnotetext{
É preciso que a educação esteja em seu conteúdo, em seus programas e em seus métodos, adaptada ao fim que se persegue: permitir ao homem chegar a ser sujeito, construir-se como pessoa, transformar o mundo, estabelecer com outros homens relações de reciprocidade, fazer a cultura e a história.
}

Os diferentes aspectos sobre a natureza do pensamento cartesiano (princípios de disjunção, redução e abstração) é denominado por Morin (2011) como "paradigma da simplicidade", constituindo uma inteligência cega, pois destrói os conjuntos e as totalidades, isola todos os objetos à sua volta, fazendo com que as realidades-chave 
sejam desintegradas. Tal metodologia, para alcançar o conhecimento, levaria à incapacidade de conceber a ideia do uno, do múltiplo. A complexidade seria, então:

[...] efetivamente o tecido de acontecimentos, ações, interações, retroações, determinações, acasos, que constituem o nosso mundo fenomenal. A complexidade apresenta-se com os traços inquietantes da confusão, do inextricável, da desordem, da ambiguidade, da incerteza. Daí a necessidade, para o conhecimento, de pôr ordem nos fenômenos ao rejeitar a desordem, de afastar o incerto, isto é, de selecionar os elementos de ordem e de certeza, de retirar a ambiguidade, de clarificar, de distinguir, de hierarquizar. (MORIN, 2011, p. 13).

Dessa forma, as disciplinas, que eram predefinidas, compondo um pensamento uniforme, de homogeneidade, perdem sua força. Documentos curriculares apontam para essas novas abordagens do conteúdo ou do próprio conteúdo em si, como é o caso do relatório da Unesco, ao propor o desenvolvimento do "aprender a conhecer", "um dos quatro pilares da educação" (LOPES, 2008, p. 21).

Nesse documento, defende-se uma nova relação com o conhecimento, na qual o aluno é sujeito-agente no processo de aprendizagem e deve saber o que fazer e como construir o conhecimento. Como este, há muitos outros documentos que apresentam em comum o discurso de integração curricular em virtude das mudanças dos processos de trabalho e da organização do conhecimento no mundo globalizado. Espera-se, assim, que:

O educador saiba compreender o movimento da sociedade identificando suas características básicas e as tendências de sua transformação, de modo a detectar as necessidades presentes e futuras a serem atendidas pelo processo educativo sob sua responsabilidade. (SAVIANI, 1996, p. 148-149).

Muller (apud LOPES, 2008) enfatiza a importância da tecnologia no mundo globalizado e define a prática pedagógica como uma forma de tecnologia. A tecnologia aqui é:

[...] entendida como o uso do conhecimento, meios, processos e organizações para produzir bens e serviços. Ou então, ainda mais amplamente, como uma rede que constrói programas de ação que coordenam uma rede de papéis. A própria prática pedagógica é entendida, assim, como uma tecnologia. (LOPES, 2008, p. 20).

Oliva e Muhringer (2001, p. 27) comparam a interdisciplinaridade à transversalidade, reconhecendo que:

Ambas apontam a complexidade do real e a necessidade de se considerar a teia de relações entre os seus diferentes e contraditórios aspectos. Mas diferem uma

Educação \& Formação, Fortaleza, v. 4, n. 11, p. 117-141 maio/ago. 2019

DOI: https://doi.org/10.25053/redufor.v4i11.924

http://seer.uece.br/redufor 
da outra, uma vez que a interdisciplinaridade refere-se a uma abordagem epistemológica dos objetos do conhecimento, enquanto a transversalidade diz respeito principalmente à dimensão didática.

Mais adiante, estabelecem os dois conceitos separadamente:

\begin{abstract}
A interdisciplinaridade questiona a segmentação entre os diferentes campos de conhecimento produzida por uma abordagem que não leva em conta a inter-relação e a influência entre eles - questiona a visão compartimentada (disciplinar) da realidade sobre a qual a escola, tal como é conhecida, historicamente se constituiu. A transversalidade diz respeito à possibilidade de se estabelecer, na prática educativa, uma relação entre aprender conhecimentos teoricamente sistematizados (aprender sobre a realidade e da realidade). E a uma forma de sistematizar esse trabalho e incluí-lo explícita e estruturalmente na organização curricular, garantindo sua continuidade e aprofundamento ao longo da escolaridade. (OLIVA; MUHRINGER, 2001, p. 27).
\end{abstract}

Os autores concluem que:

$\mathrm{Na}$ prática pedagógica, interdisciplinaridade e transversalidade alimentam-se mutuamente, pois o tratamento das questões trazidas pelos Temas Transversais expõe as inter-relações entre os objetos do conhecimento, de forma que não é possível fazer um trabalho pautado na transversalidade tomando-se uma perspectiva disciplinar rígida. (OLIVA; MUHRINGER, 2001, p. 28).

Floriani (2000) discute a dificuldade de estabelecer um novo sistema de conhecimento que una a natureza e a sociedade, porque foram conceitos concebidos separadamente ao longo dos últimos séculos. Além disso, a sociedade humana se constrói no interior de espaços naturais e reconstrói a natureza socialmente, o que torna difícil separar um fato natural do social ou a própria definição de natureza, sem misturar-se com ela, pois o estado natural é uma construção social.

Nesse sentido, o ser humano produz uma sociedade que também o produz e a intenção de representar a natureza por si só, independentemente da existência humana, de forma "objetiva”, não é impossível e é própria das ciências modernas, mas também é uma maneira sociocultural de representá-la. Assim, conhecimento não é um objeto igual aos demais, pois, além de servir para conhecer outros objetos, serve para conhecer a si mesmo. No entanto, o conhecimento nem basta a si mesmo, nem é um fiel reflexo da sociedade, pois se trata de uma perspectiva identificadora de um campo simbólico, cujos mecanismos são constitutivos de uma cultura científica moderna e tecnológica, com um ethos científico-corporativo já constituído. 
Atualmente, não cabe aos cientistas ou à ciência reafirmarem verdades, visto que o Homem e o Mundo já se descobriram visceralmente incertos, abrindo uma nova razão de ser, de estar e de fazer o mundo. A ciência, pois, é uma verdade humana, transitória e, quando está acima disso, torna-se religiosa (FLORIANI, 2000).

O desafio do cientista de hoje é transpor a repetição, a reprodução do conhecimento, buscando diferentes referentes cognitivos, não somente aqueles da sua disciplina científica, mas também aqueles arraigados na cultura do povo, tanto no presente quanto no passado.

\section{METODOLOGIA}

Trata-se de pesquisa participante, voltada para a Educação Ambiental, junto aos alunos de escola pública localizada no Rio de Janeiro, crianças e adolescentes na faixa etária entre 12 e 14 anos. A escola possui os dois segmentos da Educação Básica, tem cerca de 900 alunos distribuídos em 25 turmas e em dois turnos. Para a realização da pesquisa, elegeram-se três turmas do $7^{\circ}$ ano, de modo a privilegiar uma faixa etária intermediária.

Como referência para o desenvolvimento deste Projeto, utilizou-se a Metodologia da Problematização, embasada no Método do Arco, de Charles Maguerez. Trata-se de uma alternativa metodológica que procura problematizar a realidade, ou um recorte dela, com vistas à sua transformação. O Arco de Maguerez, utilizado na Metodologia da Problematização, é constituído de cinco etapas: Observação da Realidade (Problema); Pontos-Chave; Teorização; Hipóteses de Solução e Aplicação à Realidade (Prática) (BERBEL, 1998).

Para verificar a mobilização dos alunos, foi proposto a eles que separassem pilhas, celulares, baterias, latas de alumínio, papel, papelão e garrafas Pet utilizados em sua residência, trazendo-os para a escola por um período determinado. Tais resíduos sólidos foram escolhidos, primeiramente, porque são itens que compõem grande parte dos resíduos sólidos residenciais urbanos passíveis de reciclagem. Além disso, são comumente descartados de forma inadequada no município do Rio de Janeiro. Foram instaladas no pátio da escola caixas coletoras, de modo que os alunos ali depositassem os resíduos trazidos de casa. 
A partir dessa ação, iniciou-se um processo de Educação Ambiental, por meio de oficinas, com material didático confeccionado para esse fim. Integraram-se à aula interdisciplinar os campos econômico, social, cultural, ético e legal com o intuito de permitir aos estudantes uma compreensão profunda das questões envolvidas na geração até o descarte dos produtos, pré e pós-consumo.

\subsection{DA IMPLANTAÇÃO DO POSTO DE COLETA SELETIVA NA ESCOLA}

Durante uma semana, mediante avisos nas salas de aula e de cartazes afixados nos murais, fez-se a campanha de coleta seletiva, isto é, foi pedido que os discentes separassem em suas casas os seguintes resíduos: pilhas, celulares, baterias, latas de alumínio, papel, papelão e garrafas Pet e que trouxessem resíduos separados e os depositassem em caixas coletoras dispostas no pátio da escola.

Tais resíduos sólidos foram escolhidos, primeiramente, porque são itens que compõem grande parte dos resíduos sólidos residenciais urbanos passíveis de reciclagem. Além disso, são comumente descartados de forma inadequada no município do Rio de Janeiro. de acordo com o relatório emitido pelo Compromisso Empresarial para Reciclagem (CEMPRE, 2014).

\subsection{SOBRE O PROCESSO DE ELABORAÇÃO DO MATERIAL DIDÁTICO}

A pesquisa norteou-se pela indagação de como é possível conscientizar os alunos sobre a importância da coleta seletiva, fundamental para o modelo de gestão integrada e sustentável dos resíduos sólidos constante na Lei n. 12.305/2010, que prevê a participação dos cidadãos, e a Escola é uma instituição que dialoga constantemente com as necessidades sociais da comunidade interna e externa a ela. A pesquisa foi realizada com alunos entre 12 e 14 anos de idade, logo pessoas em processo de formação.

O trabalho educativo voltado para o meio ambiente obriga fazer pensar sobre a organização do conhecimento e pressupõe reorganizar também as formas de ensino e mesmo de pesquisa, para favorecer uma visão sistêmica da realidade, o que exigiu uma metodologia interdisciplinar, complexa, como diria Edgar Morin (2011). Nesse sentido, o 
conteúdo das palestras (aulas para os alunos antes e depois do período de coleta seletiva) exigiu a confecção de material didático próprio, em que se buscou integrar saberes constantes em várias disciplinas.

Tal material foi formulado com base nas reflexões sobre a sociedade de consumo, causas e consequências da geração e destino incorreto dos resíduos sólidos, reformulação do conceito de "lixo" e revisão do conceito de sustentabilidade, com o desenvolvimento da Educação Ambiental pautada na ação de alunos.

\subsection{SOBRE OS MATERIAIS UTILIZADOS NA PESQUISA}

Para a realização das aulas interdisciplinares de Educação Ambiental sobre resíduos sólidos, foram utilizados os seguintes materiais: avisos, material didático interdisciplinar de Educação Ambiental sobre resíduos sólidos, cartazes, que foram elaborados pelos alunos, visando à interação entre discente e conhecimento de forma lúdica; computador conectado a projetor, com acesso à internet, para reproduzir vídeos sobre Educação Ambiental e matérias jornalísticas sobre a logística reversa e sobre a poluição da Baía de Guanabara, devido aos resíduos sólidos e esgoto lançados ao mar; caixas de som; cola branca para finalizar os cartazes em conjunto com os estudantes; caixas de papelão identificadas para recolher os materiais, folhas reutilizadas; hidrocor, lápis de cor, cola, tesoura, revistas, caixas de papelão; resíduos sólidos inorgânicos, como embalagens, papéis, sacolas plásticas para confeccionar os materiais reaproveitados que decoram o ambiente da sala de aula e questionário avaliativo do projeto.

$\mathrm{Na}$ sala de aula, as cadeiras foram colocadas em forma de círculo, para possibilitar a interação dos alunos entre si e a mediação com os pesquisadores; mesa com termos de consentimento, avaliação pós-oficina, canetas e brindes. Foram desenvolvidas ações para tornar a aula atraente e lúdica: um lanche foi servido na culminância da atividade. A sala de aula foi decorada com temas ligados ao meio ambiente; construção ativa do conhecimento, por meio da complementação dos cartazes pelos alunos. 


\subsection{DESCRIÇÃO DAS ETAPAS}

\section{Quadro 1 - Etapas}

\begin{tabular}{|c|c|c|}
\hline Etapas & Processo & Tempo \\
\hline I & $\begin{array}{l}\text { Objetivos: Despertar o interesse dos alunos para o tema. } \\
\text { Verificar o nível de adesão prévia, sem interferência do material didático. } \\
\text { Nesta etapa, afixam-se avisos }{ }^{1} \text { nas salas de aula, solicitando a separação dos } \\
\text { resíduos sólidos recicláveis especificados. Os alunos também são avisados } \\
\text { verbalmente sobre a campanha da coleta seletiva, a ser realizada nas caixas } \\
\text { coletoras }^{2} \text { dispostas no pátio. }\end{array}$ & 5 dias* $^{*}$ \\
\hline II & $\begin{array}{l}\text { Objetivo: Sensibilização e divulgação para a participação voluntária na aula de } \\
\text { Educação Ambiental interdisciplinar. } \\
\text { Findo o período da Etapa I, visitam-se }{ }^{2} \text { as turmas e faz-se uma pequena } \\
\text { apresentação dos principais objetivos da aula interdisciplinar de Educação } \\
\text { Ambiental, explicando como serão a dinâmica do evento e as possibilidades de } \\
\text { reverter em benefício próprio o valor arrecadado com a venda dos materiais } \\
\text { trazidos pelos alunos. } \\
\text { Explica-se a necessidade do consentimento do aluno em participar da pesquisa e } \\
\text { a anuência do seu responsável, distribuindo-se, a partir de então, os termos de } \\
\text { consentimento para os que demonstrem interesse em participar, bem como o } \\
\text { termo de consentimento dos responsáveis para que o aluno solicite a assinatura } \\
\text { do mesmo e entregue no dia da aula interdisciplinar de Educação Ambiental. } \\
\text { Um dia antes do evento, a pesquisadora retorna ao colégio para reforçar o } \\
\text { convite para participarem do evento e para recolher os termos de consentimento } \\
\text { dos responsáveis dos alunos. }\end{array}$ & 3 dias* $^{*}$ \\
\hline III & $\begin{array}{l}\text { Aula interdisciplinar }{ }^{3} \text { com aplicação do material didático interdisciplinar sobre } \\
\text { Educação Ambiental e informação sobre o incentivo material, ou seja, aviso de } \\
\text { que com o valor arrecadado pela venda dos resíduos sólidos provenientes da } \\
\text { coleta seletiva, será feito um lanche coletivo. }\end{array}$ & 2 dias $^{*}$ \\
\hline IV & Coleta seletiva dos resíduos sólidos. & 5 dias $^{*}$ \\
\hline V & $\begin{array}{l}\text { Culminância: Retorno da pesquisa com dados sobre a arrecadação dos resíduos } \\
\text { sólidos. Escolha dos trabalhos da campanha "Seja consciente!". Lanche coletivo } \\
\text { com o valor arrecadado pela venda dos resíduos sólidos recicláveis trazidos pelos } \\
\text { alunos. }\end{array}$ & $1 \mathrm{dia}^{*}$ \\
\hline & Total & 16 dias $^{*}$ \\
\hline
\end{tabular}

Fonte: Elaboração própria (2019).

Depois do trabalho desenvolvido com o material didático proposto, pretendeu-se verificar se houve um aumento ou não da adesão dos alunos no projeto de coleta seletiva, evidenciando se a Educação Ambiental, em consonância com o incentivo

1 Os alunos serão avisados pela pesquisadora, além de serem informados por meio dos cartazes afixados nas salas de aula.

2 Caixas de papelão que serviram para acondicionamento de produtos serão reaproveitadas como caixas coletoras, as quais serão encapadas com papéis cuja cor e símbolo da reciclagem indicarão o tipo de resíduo a ser descartado. A intenção é reproduzir um modelo que já existe na realidade, os Postos de Entrega Voluntária.

3 O material didático foi elaborado pela mestranda. Este irá compor o produto final da pesquisa, para que possa ser utilizado em outros momentos.

* Foram considerados dias úteis.

Educação \& Formação, Fortaleza, v. 4, n. 11, p. 117-141 maio/ago. 2019

DOI: https://doi.org/10.25053/redufor.v4i11.924

http://seer.uece.br/redufor 
material, efetivamente colabora para a conscientização ambiental e o consequente engajamento dos alunos.

\subsection{DIVULGAÇÃO DA AULA INTERDISCIPLINAR SOBRE EDUCAÇÃO AMBIENTAL}

Com a intenção de despertar o interesse dos alunos com relação à participação nas oficinas interdisciplinares, realizadas no contraturno, sobre resíduos sólidos, foram desenvolvidas algumas ações de divulgação entre os discentes, como descrito a seguir: visitas às turmas, quando se realizou uma pequena apresentação dos principais objetivos da oficina, fazendo uma explanação sobre a dinâmica da aula, com a relevância dos seguintes tópicos: 1) possibilidade de reverter o valor arrecadado pela venda dos resíduos sólidos coletados em um lanche coletivo no dia da culminância; 2) jogo interativo com premiação; concurso de imagem para a campanha "Seja consciente!"; 3) necessidade do consentimento do aluno em participar da pesquisa e anuência do seu responsável, tendo sido distribuídos, a partir de então, os termos de consentimento para os que demonstraram interesse em participar, bem como o termo de consentimento dos responsáveis para que o discente solicitasse a sua assinatura e entregasse no dia da oficina; 4) um dia antes do evento, a pesquisadora retornou ao colégio para reforçar o convite para participarem do evento e para recolher os termos de consentimento dos responsáveis dos alunos; 5) importância sobre o conhecimento a ser construído para sua formação como cidadão e para o meio ambiente, revisão dos conceitos que permeiam a questão dos resíduos sólidos e reflexão sobre a realidade complexa, por meio de uma aula interdisciplinar atraente, criativa e dinâmica.

\subsection{PROPOSTA PEDAGÓGICA DESENVOLVIDA EM CADA DISCIPLINA E SOCIALIZADA COM A COMUNIDADE ESCOLAR}

- Motivação à reflexão dos alunos, propiciada por um pensamento, um filme, uma notícia, uma imagem, etc.: recursos pedagógicos para a sistematização do conhecimento das questões por meio de textos, os quais fazem parte do material didático;

Educação \& Formação, Fortaleza, v. 4, n. 11, p. 117-141 maio/ago. 2019

DOI: https://doi.org/10.25053/redufor.v4i11.924

http://seer.uece.br/redufor 
- Participação conjunta por meio de debates sobre assuntos pertinentes ao tema e condizentes com as aulas propostas no material didático;

- Produção dos alunos por meio de pesquisas e elaboração de cartazes, redação, desenhos, charges e objetos reciclados;

- Culminância por meio da análise da quantidade de resíduos sólidos recolhidos e do valor arrecadado, revertido em um lanche coletivo;

- Avaliação dos alunos sobre a aula interdisciplinar de Educação Ambiental, sobre a participação no Projeto de Reciclagem e seu interesse em reproduzir a coleta seletiva em suas residências;

- Recursos tecnológicos (projetor) para tornar a aula mais dinâmica;

- Afetividade por meio da relação horizontal entre mediador e alunos, músicas, etc.

\section{RESULTADOS E DISCUSSÃO}

Constatou-se que, em uma escola de médio a grande porte - como na que se realizou a pesquisa -, produz-se grande quantidade de resíduo sólido reciclável, o que impactou nos resultados da pesquisa, que previam somente a arrecadação de recicláveis trazidos da residência do alunado.

Ao longo do projeto, os funcionários de setores como secretaria, biblioteca, reprografia e cantina, responsáveis por atividades que descartam muito papel e caixas de papelão, interessaram-se em doar esses materiais para a coleta seletiva, fazendo com que um público não previsto fosse alcançado pela ação. Servidores de outras seções também se interessaram pelo projeto, fazendo perguntas sobre os objetivos e 0 que seria feito com os resíduos sólidos arrecadados.

Alunos dos anos do Ensino Fundamental e Médio que não participaram das aulas de Educação Ambiental também despertaram interesse em participar diante do Posto de Entrega Voluntária montado no pátio da escola.

Concluiu-se que o simples fato de instalar um Posto de Coleta Voluntária, com as devidas informações sobre os objetivos desta prática, torna possível que pessoas que apresentem uma consciência ambiental prévia realizem a coleta seletiva.

Educação \& Formação, Fortaleza, v. 4, n. 11, p. 117-141 maio/ago. 2019 
Essa ideia de que a ausência da disponibilidade de caixas coletoras inviabiliza um movimento inicial de participação na coleta seletiva é reforçada pela indagação de muitos alunos durante as aulas, sobre onde descartar os resíduos sólidos após a triagem na residência. Muitos alunos perguntaram: "Onde descartar os resíduos sólidos se não encontro caixas coletoras para este fim?'.

A pesquisadora orientou os estudantes a levarem os recicláveis diretamente a um posto de venda de resíduos sólidos, popularmente conhecidos como "ferro-velho". Os alunos que moram em bairros atendidos pelo programa de coleta seletiva da Companhia Municipal de Limpeza Urbana (Comlurb) questionaram o fato de o caminhão da coleta "misturar" todos os resíduos sólidos que haviam sido separados pelos moradores em sua residência.

Essa observação reforça o fato de que ações devem ser atreladas à disposição da informação junto à população, visto que, já pela descrença de seu propósito (coleta seletiva), devido à disposição aleatória de todos os resíduos juntos no caminhão de coleta, causa-se a perda da credibilidade do que é proposto, o que desmotiva as pessoas a participarem do processo.

Na segunda etapa do Projeto, com as aulas e atividades de Educação Ambiental e o incentivo material (retorno dos valores com a venda dos resíduos sólidos), houve um aumento dos recicláveis, a saber:

\begin{tabular}{|c|c|c|}
\hline \multicolumn{2}{|c}{ Quadro - 2 Relação de descartáveis reciclados } \\
\hline Resíduo sólido & $\begin{array}{c}\text { Etapa I (antes do } \\
\text { desenvolvimento de atividades } \\
\text { de Educação Ambiental) }\end{array}$ & $\begin{array}{c}\text { Etapa II (depois do } \\
\text { desenvolvimento de atividades } \\
\text { de Educação Ambiental) }\end{array}$ \\
\hline Lata de alumínio & 29 unidades & 255 unidades \\
\hline Garrafa Pet & 57 unidades & 362 unidades \\
\hline Papel/papelão & 660 gramas & 20 quilos \\
\hline Pilha/celular/bateria & 17 unidades & 182 unidades \\
\hline Copo de plástico duro & - & 104 unidades \\
\hline
\end{tabular}

Fonte: Elaborada pelos autores.

Após o desenvolvimento das atividades de Educação Ambiental, observou-se que copos plásticos de guaraná, não solicitados previamente e consumidos na cantina, foram descartados nas caixas coletoras. 
Muitos alunos disseram gastar muitas pilhas no controle do videogame e surpreenderam-se em saber em uma das palestras que uma pilha é capaz de poluir 20.000 litros de água por quase 500 anos.

A junção Educação Ambiental e retorno material permitiu aos alunos o entendimento de que preservar o meio ambiente significa beneficiar a toda a coletividade, além de possibilitar entender que o resíduo sólido tem valor financeiro, pois a venda dos recicláveis financiou o lanche coletivo, momento de descontração e comemoração pelos resultados alcançados. O questionário avaliativo reforçou a aprovação da metodologia pelos alunos e a intenção de reproduzir a triagem em suas residências.

\section{CONSIDERAÇÕES FINAIS}

Conforme Floriani (2000), o desafio do pesquisador é ousar transpor a repetição, alterando os procedimentos convencionais na (re)produção do conhecimento, buscando a fonte de sua imaginação em diversos referenciais cognitivos; não apenas naqueles de sua disciplina científica, mas também nos de natureza estética e ética, nos conhecimentos espontâneos, especialmente naqueles profundamente arraigados na cultura dos povos (do presente e do passado), recriando e restabelecendo o que foi esquecido ou obscurecido pelos procedimentos da racionalidade instrumental da modernidade.

A metodologia adotada no trabalho buscou contemplar diferentes disciplinas, de modo a conscientizar e formar novos hábitos nos educandos no que diz respeito aos resíduos sólidos residenciais no pós-consumo, mas também em um momento anterior, que é o de consumo consciente. Buscou-se criar uma consciência crítica, demonstrando que os resíduos envolvem aspectos ambientais, econômicos, sociais e éticos, portanto permeando todas as disciplinas.

O material didático produzido buscou motivar no aluno o interesse pelas questões ambientais, evidenciando-se os resultados dos impactos ambientais diretamente na vida individual e coletiva. Foi enfatizado que o problema dos resíduos sólidos começa quando se adquire um produto que cada vez em menor tempo é descartado. 
O trabalho realizado pretendeu também despertar a curiosidade sobre a pesquisa, o enaltecimento da autoestima do aluno e o afloramento de sua iniciativa e criatividade, pois, em sintonia com a Unesco, o conhecimento é construído por meio do desenvolvimento das competências: "aprender a conhecer, aprender a fazer, aprender a viver juntos e aprender a ser".

A Educação Ambiental está diluída nas diferentes disciplinas curriculares. Os conhecimentos construídos em sala de aula foram socializados com toda a escola, por meio de atividades de exposição dos cartazes produzidos pelos alunos e dos objetos reutilizados feitos durante as oficinas. A Educação Ambiental, por esse viés, é altamente "política" (no sentido da consciência e participação cidadã), ao permitir aos futuros cidadãos o exercício de direitos e deveres necessários para garantir um ambiente limpo e saudável.

A escola, em sintonia com os anseios da sociedade, pode ser um dos espaços propulsores do encadeamento cultural de hábitos e atitudes comprometidas com 0 destino responsável dos resíduos sólidos.

\section{REFERÊNCIAS}

BERBEL, N. "Problematization" and problem-based learning: Different words or different ways? Interface: Comunicação, Saúde, Educação, Botucatu, v. 2, n. 2, p. 139-154, 1998.

BODAH, E. T. Pesquisa científica e gestão ambiental para um planeta com sete (ou mais) bilhões de habitantes: desafios e perspectivas. In: BODAH, E. T. (Org.). Conversas entre educadores: novos diálogos. Passo Fundo: Thaines \& Bodah Center for Education and Development, 2012.

BRASIL. Lei n. 12.305, de 2 de agosto de 2010. Institui a Política Nacional de Resíduos Sólidos; altera a Lei n. 9.605, de 12 de fevereiro de 1998; e dá outras providências. Diário Oficial [da] República Federativa do Brasil, Poder Executivo, Brasília, DF, 3 ago. 2010.

BRASIL. Ministério do Meio Ambiente. Cidadania e consumo sustentável. Disponível em: <http://www.mma.gov.br/estruturas/sedr_proecotur/_publicacao/140_publicacao0906200 9025703.pdf> Acesso em: 5 mar. 2014.

BRAVO, I. A educação ambiental e as diversas correntes pedagógicas. In: HAMMES, V. S. (Org.). Proposta metodológica de macroeducação. 2. ed. São Paulo: Globo, 2004.

CEMPRE - Compromisso Empresarial para Reciclagem. Ciclosoft: radiografando a coleta seletiva. 2014. Disponível em <http://cempre.tecnologia.ws/ciclosoft_2014.php>. Acesso em: 20 out. 2014. 
COBRA, M. Serviços: como construir valor para o cliente. São Paulo: Marcos Cobra, 2004.

FERRAZ, J. M. G. Educação Ambiental e mudança de valores. In: HAMMES, V. S. (Org.). Proposta metodológica de macroeducação. 2. ed. São Paulo: Globo, 2004.

FLORIANI, D. Marcos conceituais para o desenvolvimento da interdisciplinaridade. In: PHILIPPI Júnior, A. (Org.). Interdisciplinaridade em ciências ambientais. São Paulo: Signus, 2000. p. 95-107.

FREIRE, P. Conscientização: teoria e prática da liberdade. São Paulo: Moraes, 1980.

KUMAR, K. Da sociedade pós-industrial à pós-moderna: novas teorias sobre o mundo contemporâneo. 2. ed. Rio de Janeiro: Jorge Zahar, 2006.

LIBÂNEO, J. C. Democratização da escola pública: a pedagogia crítico-social dos conteúdos. São Paulo: Loyola, 1998.

LOPES, A. R. C. Políticas de integração curricular. Rio de Janeiro: UERJ, 2008.

MARANHO, G.; RIBEIRO, F. V. A publicidade e o consumo. Maringá: UEM, 2008.

MELLO E SOUZA, N. Educação Ambiental: dilemas da prática contemporânea. Rio de Janeiro: Thex, 2000.

MILLER, J. R. Biodiversity conservation and the extinction of experience. Trends in Ecology \& Evolution, Cambridge, v. 20, p. 8, p. 430-434, 2005.

MORIN, E. Introdução ao pensamento complexo. Porto Alegre: Sulina, 2011.

OCDE - Organização para a Cooperação Econômica e Desenvolvimento. Manual de Oslo: diretrizes para a coleta e interpretação de dados sobre inovação tecnológica. Brasília, DF: Finep, 1996.

OLIVA, J. T.; MUHRINGER, S. M. A introdução da dimensão ambiental no ensino formal. In: LEITE, A. L. T. A.; MININNI-MEDINA, N. (Org.). Educação Ambiental: curso básico a distância: educação e educação ambiental II. 2. ed. Brasília, DF: MMA, 2001. p. 17-31.

PUCCI, F. G. Biometanização da fração orgânica do resíduo sólido urbano: uma revisão do estado da arte. 2013. 61 f. Monografia (Graduação em Engenharia Química) Programa de Graduação em Engenharia Química, Universidade Federal de São Carlos, São Carlos, 2013.

ROCHA, J. C.; ROSA, A. H.; CARDOSO, A. A. Introdução à Química Ambiental. 2. ed. Porto Alegre: Bookman, 2009.

SAVIANI, D. Pedagogia histórico-crítica: primeiras aproximações. Campinas: Autores Associados, 1996. 
SOARES, J. B. C. Prefácio. In: MELLO E SOUZA, N. Educação Ambiental: dilemas da prática contemporânea. Rio de Janeiro: Universidade Estácio de Sá, 2000. Prefácio.

TIGRE, P. B. Gestão da inovação: a economia da tecnologia no Brasil. Rio de Janeiro: Elsevier, 2006.

YUNES, E. Um nome para o pecado. In: BINGEMER, M. C. L. et al. (Org.). Pecados. Rio de Janeiro: PUC, 2001. p. 7-13.

\section{Roy Reis Friede (Brasil, Rio de Janeiro, Rio de Janeiro) - Universidade Federal do Estado do Rio de Janeiro (Unirio)}

Doutor em Direito Público pela Universidade Federal do Rio de Janeiro (UFRJ). Desembargador Federal. Professor titular e membro do conselho consultivo do Mestrado Profissional Multidisciplinar em Desenvolvimento Local do Centro Universitário Augusto Motta (Unisuam). Professor adjunto da Unirio.

Lattes: <http://lattes.cnpq.br/6180019303336522>.

E-mail: <assessoriareisfriede@hotmail.com>.

\section{Danielle de Souza Reis (Brasil, Rio de Janeiro, Rio de Janeiro) - Centro Universitário Augusto Motta (Unisuam)}

Mestra em Desenvolvimento Local pelo Unisuam. Participa do Projeto Implicações do Ambiente no processo de Ensino-Aprendizagem: Estudos sobre Escolas Públicas do Complexo do Alemão. Docente da rede municipal de educação do Rio de Janeiro. Servidora do Colégio Pedro II.

Lattes: <http://lattes.cnpq.br/8754286776291327>.

E-mail: <daniellesr46@gmail.com>.

\section{Katia Eliane Santos Avelar (Brasil, Rio de Janeiro, Rio de Janeiro) - Centro Universitário} Augusto Motta (Unisuam)

Doutora em Ciências pela Universidade Federal do Rio de Janeiro (UFRJ). Coordenadora do Laboratório de Referência Nacional para Leptospirose do Instituto Oswaldo Cruz (Fiocruz). Professora titular e pesquisadora do Programa de Pós-Graduação Profissional Interdisciplinar em Desenvolvimento Local do Unisuam.

Lattes: <http://lattes.cnpq.br/6772085183251168>.

E-mail: <katia.avelar@gmail.com>.

\section{Maria Geralda de Miranda (Brasil, Rio de Janeiro, Rio de Janeiro) - Centro Universitário Augusto Motta (Unisuam)}

Pós-Doutora em Estudos de Literaturas Africanas de Língua Portuguesa pela Universidade Federal do Rio de Janeiro (UFRJ), em Políticas Públicas e Formação Humana pela Universidade do Estado do Rio de Janeiro (UERJ) e em Narrativas Visuais pela Universidade Clássica de Lisboa (UCL). Professora do Programa de Pós-Graduação em Desenvolvimento Local do Unisuam.

Lattes: <http://lattes.cnpq.br/6730722686472778>.

E-mail: <mgeraldamiranda@gmail.com>.

Recebido em 14 de janeiro de 2019.

Aceito em 28 de fevereiro de 2019.

Educação \& Formação, Fortaleza, v. 4, n. 11, p. 117-141 maio/ago. 2019

DOI: https://doi.org/10.25053/redufor.v4i11.924

http://seer.uece.br/redufor 